\title{
A language focused approach to supporting children with social, emotional and behavioural difficulties (SEBD)
}

Children with Social, Emotional and Behavioural Difficulties have been shown to constitute a unique class of Special Educational Need, where their 'challenging' behaviour can often result in a disproportionately punitive response, rather than one characterised by a needs-based understanding of behaviour as communication. Such an understanding underpins relational approaches to behaviour management in school where a will to develop, maintain, repair and sustain attachments is key. In addition, the centrality of language to the success of such approaches has also been identified. This paper explores a relational approach in school within the context of Nurture Groups, Restorative Practice and positive language and communication. It concludes that to enact a principle of inclusion for troubled children, we need to create facilitating environments in school that are consistent, equitable and that promote trust, through naturalistic opportunities for positive language and communication.

\section{Introduction:}

In line with the aims of this special issue to consider how provision for children with SEND (Special Educational Needs and Disabilities) is conceptualised, operationalised and enacted, (Rix, Sheehy, Fletcher-Campbell, Crisp and Harper, 2013), this paper examines a particular category of SEND: children with Social, Emotional and Behavioural Difficulties (SEBDs). It explores the practical provision for such children within a particular context: primary and also secondary schools in England. It is important to note that since the publication of the new SEND Code of Practice 0-25 (DfE, 2015), SEBD has been superseded by a move to categorise such children under the umbrella term Social Emotional and Mental Health difficulties (SEMH). However, we feel it is useful to continue using the SEBD acronym in this special issue article. This is due to the explicit focus on 'behaviour' that the term brings to mind, which is the primary interest behind our exploration and which differentiates the children we are talking about here, from other manifestations of SEMH difficulty.

It has been suggested that SEBDs represent a special class of SEND in school "because unlike other SEND designations, educators remain confounded by how best to respond to students whose particular special educational need seems to justify punitive disciplinary action, including exclusion" (Jull, 2008; p.13). 
As such it is important to examine how SENDs that are typified by social and emotional challenge rather than explicit cognitive disability can be best supported in school. This broad category of children and young people is notoriously challenging for inclusive school environments and indeed such children are often labelled as having 'challenging behaviour' a label that implies the perspective of the educative environment that the young person should supposedly conform to. Challenging, or perhaps challenged?

The Social, Emotional and Behavioural Difficulties Association (SEBDA) define this group of children as both troubling and troubled (2019). As a broad sub-category of SEND this group includes children who have suffered various known childhood traumas such as those categorised within the ACEs (Adverse Childhood Experiences) research. Such troubled and challenged children require extra support in their learning and in their everyday handling of a school environment. Yet, in an attempt to manage SEBDs in an inclusive way through mainstream placement, they can become labelled as 'difficult', 'anti-social' and 'uncooperative', resulting in various forms of exclusion as school staff attempt to manage the wellbeing and learning of the whole class. In recent cases, reported in the media a child with ADHD received an 'isolation booth sanction' for 60 days, and more recently a pupil with autism and mental health problems tried to take her own life as a result of being sanctioned to an isolation booth for more than a month (Perraudin, 2018, 2019). Exclusionary responses range from temporary removal from class to permanent exclusion from school, responses which are based on a rational management strategy focused on respite and the 'greater good' of the whole class. However, such responses are also likely to be indicative of a 'will to punish' (Parsons, 2005) a child who appears unlikeable.

This paper will firstly examine the principle of inclusion, before going on to examine the challenges of enacting an inclusionary approach in school for children with SEBD. It will then examine why punitive strategies are unlikely to work before going on to discuss two strategies for responding to children with SEBD: Restorative Practice (RP); and Nurture Groups. It will then present the evidence from the research field that upholds the idea that these two approaches offer a way to engage children and young people an inclusive way within a mainstream context.

\section{Inclusion:}

The inclusion of SEND became an increasingly prominent part of educational policy and practice in England as a result of the Warnock Report (1978) and the Education Act (1981). These policy developments changed the way SEND was viewed and understood, through the introduction of "statements" of SEND and an "integrative" approach based on common educational goals for all children. 
The UN Salamanca statement of 1994 extended the idea that mainstream schools must meet the needs of children with SENDs" (UNESCO, 1994), emphasising a to universal 'right to education' as enshrined by the Universal Declaration of Human Rights and reinforced in the World Declaration on Education for All (UNESCO, 1990). Over the next two decades, inclusion became the norm outlined in such policy documents as SENDA (2001), the SEN Code of Practice (2001), and the SEN Strategy (2004). Fast forwarding to more recent legislation under the Conservative-Liberal Democrat Coalition, the SEND Code of Practice (2014) has a strong focus on removing barriers to learning through disallowing schools to refuse students with SEND, and also strengthening the ability of parents and professionals to petition LEA's for Education Health and Care plan (EHC) assessment.

However, the extent to which inclusion takes place within schools in the UK depends to a large extent on how inclusion is defined. Interpretations are subject to two related political agendas in England. Firstly a 'standards agenda', influenced by international league table comparisons of academic achievement, results in a narrow mainstream curriculum which may be inaccessible to SEND students (Lloyd, 2008). Secondly, the current 'austerity agenda', implemented since 2010 by the Conservative-Liberal Democrat government and continued under the present Conservative Government, has created a cost effectiveness approach to inclusion. Consequently, there are now fewer specialist SEND units and an impoverished provision within mainstream classes. Government statistics show that between 2017/2018, SEND provision dropped from 3,489 to 3,157 places (DfE, 2018). This is accompanied by an apparent unwillingness on the part of Local Education Authority's (LEAs) to assess children for SEND due to the additional costs associated with the requirement from the 2014 SEND reforms for LEAs to develop and make accessible a comprehensive 'local offer' of SEND provision (DfE, 2011). There is evidence that this may have resulted in provision only for the children of those parents who are most effective in making their voices heard or have the most support from their respective schools (Tickle, 2017).

Echoing definitional concerns highlighted above, Willman \& Seeliger (2017) identify a lack of clarity in researchers' usage of 'inclusion'. We take a broad view of inclusion to mean SEND children being taught alongside non-SEND peers in mainstream school to the maximum appropriate extent, in line with such guidance as provided by the Special Educational Needs and Disability Act (2001) and the Least Restrictive Environment mandate (Yell, 1998). However, we also recognise that for certain children, inclusion in a "setting or settings that best meets their needs and helps them achieve their potential" (House of Commons, 2006; Online) becomes a more pragmatic and appropriate aim of inclusion. Our understanding of inclusion therefore is one that is aligned with 
the SEN Strategy (DfES, 2004) where we see inclusion as being less about 'place', and much more about "the type of school that children attend: it is about the quality of their experience; how they are helped to learn, achieve, and participate fully in the life of the school" (DfES, 2004; p 25). Overall therefore, we see inclusion as ranging from the narrow aims of classroom placement and meeting student social/academic needs to the broader goals of nonmarginalisation for all students and the creation of community (Ainscow, Booth, and Dyson, 2006; Göransson and Nilholm 2014).

\section{The challenges of enacting an inclusion principle for SEBD:}

There is strong evidence that certain SEND students experience differential treatment when it comes to schooling and their experiences with teachers and peers within it. Jull (2008) has suggested that "EBD [emotional and behavioural disorders] is perhaps the only SEN category that exposes a child to an increased risk of exclusion, simply as a function of the SEN in the first instance" (p.13). Soodak, Podell \& Lehman (1998) have reported teachers describing SEBD students as "among the least desirable to have in general education classrooms" (In Wagner et al, 2006; p.14). Whilst Hajdukova (2014) reports students with SEBD describing "unpopularity and dislike among peers... as a salient feature of their mainstream school experience" (p.160).

Another group of children who can often exhibit similar behaviour as children with SEBD, are those who have experienced Adverse Childhood Experiences (ACEs). Children who have been impacted by ACEs often adopt "behaviours or patterns of thinking that put them on a path for further trauma... as a result of consequences for their actions that do not fit within societal rules and norms" (McInerney \& McKlindon, 2014; p.5). Staff are often ill-equipped to handle these behaviours, that can be extreme, unpredictable and personally challenging (Hodas, 2006). As a result, recommendations from trauma-informed practice that directly contrast with zero-tolerance policies have been made, to train staff on the impacts of trauma and avoid the possibility of 're-traumatizing' the child:

"Know the child's triggers and avoid the need for punitive action. By recognizing children who have been exposed to trauma and creating an environment that allows them to feel safe, many behavioral problems and disciplinary measures such as detentions, suspensions, and expulsions can be avoided." (McInerney \& McKlindon, 2014; p. 17)

However, this kind of trauma-informed approach seems to be one that is not often taken in schools; looking at recent DfE statistics on exclusion it is likely that SEBD accounts for a high proportion of school exclusions given that in 2016/2017, SEND pupils represented around half of all permanent exclusions 
(44.9\%), and that persistent disruptive behaviour was the single biggest factor for sanctions, making up 28.4\% of all fixed-term exclusions (DfE, 2018). In punitive and 'zero tolerance' systems of discipline SEBD pupils are likely to experience differential treatment from both teachers and peers.

Why don't punitive strategies work for children and young people with SEBD? Recent research on ACEs has suggested that organizational cultures of schools that are aligned with zero-tolerance policies towards problematic behaviour can result in a belief that addressing student's traumatic experiences is viewed as "being soft" (Hodas, 2006; Walkley \& Cox, 2013). Furthermore, for many children who do not have SEBDs or backgrounds characterised by ACE, discipline is often seen to bring them quickly into line. Therefore, the reality may be reflective of a more complex difficulty in knowing how to best respond to certain children's personally challenging behaviour, in a manner that is equivalent for all students. It may also reflect a difficulty in knowing how to differentiate between the normal challenging behaviour of non-traumatized students, and atypical behaviour that has resulted from early trauma or SEBD. This is perhaps why zero-tolerance policies are seen as being effective and fair - treating all children regardless of background in the same way provides an easily implementable and uniform policy that loosely papers over any perceived ethical cracks.

However, it is becoming increasingly clear that zero-tolerance does not work for schools, for the children and young people themselves, or for their families. As suggested by Procter-Legg (2018), if sanctions did work "our exclusion rates would not be so high; those same children would not be in trouble each time; and our alternative-provision sector would not be full to bursting point" (p.52). The negative impact of overly punitive disciplinary practices has been noted by a number of authors who collectively suggest that the will to punish is counterproductive because it represents an overreaction which can result in a clear worsening of student's behaviour (Greenwood, 2002; Kupchik, 2010; Warin \& Hibbin, 2016a). In addition, it also results in the alienation of children from the curriculum through exclusionary practices, and the erosion of the "moral authority" of the school (Irby, 2014; p.529). Furthermore, it has been suggested that "counterproductive school discipline policies and procedures...have a negative overall impact on... social outcomes" (Pane \& Rocco, 2014: In Nicoll, 2014; p.58), none of which is so obvious as the school-prison pipeline (Irby, 2014).

\section{Nurture Groups and Restorative Practice:}


Two strategies in school for the inclusion of children with SEBDs include Nurture Groups (NGs) and Restorative Practice (RP). We connect these two approaches because they both align with the definition of inclusion that we presented above that stresses the quality of children's school experiences. Both kinds of school practice emphasise the quality and support of relationships within the school setting, between staff members and their pupils, and pupils and their peers. Both strategies have been the empirical focus of recent research undertaken by this research team.

NGs were first conceived by Marjorie Boxall in the 1970s for children with apparent attachment difficulties (Boxall, 2002) and corresponding behavioural problems preventing them from thriving within a mainstream class. The aim of NGs is to provide the child with social and emotional experiences designed to address some of this early deprivation, and fill gaps in their psychosocial development (Cooper \& Tiknaz, 2007). Restorative Practice (RP) is a relational approach derived from the criminal justice system that has gained popularity in school settings over the last 10 years (Hopkins, 2011). The key principles of RP focus on maintaining relationships and restoration from conflict, through a fair and neutral process that is respectful, safe and voluntary. As such it "views harm not primarily as a violation of rules or laws, but as a violation of people and relationships (Zehr, 2002)" (Reimer, 2015; p.7). Punishment for such acts of harm is viewed by RP as being counterproductive, shaming and stigmatizing, pushing offenders into a negative self-view that ultimately fails to change their behaviour (Braithwaite, 1989). Instead RP aims to bring the victim and offender into communication, asking questions that give everyone an equal voice, repairing the harm rather than assigning punishment and blame.

The link between NGs and RP relates to Attachment Theory's concern with sustaining relationships with a child's significant others. As such the importance of repairing relationships as emphasised by RP provides the clear link to NGs and attachment theory. In addition, one of the six principles of Nurture, as originally proposed by Marjorie Boxall (2002) is to perceive behaviour as communication. This is the recognition that it is easier to for children to enact their emotions in the absence of an ability to verbally express what they may be feeling inside.

Enabling teachers to understand the principle that all behaviour is communication is a key aspect of Nurture and also RP provision in school, where both "...philosophies are based on a will to develop, maintain, repair and sustain attachments" (Warin \& Hibbin, 2016a; p. 7). The similarities between the two approaches are reinforced by the fact that a number of practitioners that we have talked to during our empirical research have readily connected both 
approaches. They perceive an affinity between RP and Nurture as both stem from the same ideological base of developing secure and trusting interpersonal relationships to support children whose non-verbal communication expresses their emotional need.

Therefore, Nurture and RP can both be understood as having a tacit emphasis on language and communication, in a similar vein to tried and tested teaching wisdom that urges children to 'use your words' rather than externalising their negative feelings through physical aggression.

\section{Broad theoretical approach and specific focus on language:}

Much of the research that has already been conducted on ways to strengthen pupil's Social and Emotional Learning (SEL) ranges from interventions focused on prosocial skills (e.g. Incredible Years Classroom Social Skills and ProblemSolving Curriculum: Webster Stratton \& Reid, 2004) to classroom-based activities such as roleplay, and interventions designed to improve social communication such as Social Stories (Gray \& Garand, 1993). These activities are focused on teaching children how to understand the thoughts and intentions of others. They also share an emphasis on the centrality of language and communication, emphasising the fact that "children at risk for behaviour problems often have language delays and limited vocabulary to express their feelings" (Webster-Stratton \& Reid, 2004; p.100), which results in a corresponding difficulty in their ability to regulate emotional responses.

However, it is much less common to see positive language and communication as a central aim and outcome of SEL interventions. This is somewhat surprising given the strong link between behaviour problems and expressive language difficulties that has been highlighted in the literature, which is particularly pertinent for students who are labelled as having SEBD (Gualtieri et al., 1983; Beitchman et al, 1989; Cohen et al., 1993). Some interventions are focused on improving emotional literacy, but they are often somewhat artificial and are explicitly 'taught' to students, rather than representing more naturalistic opportunities for students to engage with positive language and communication.

In contrast, Hromek \& Roffey (2009) argue that the use of therapeutic board games provides a meaningful way to facilitate SEL where there is a context for "transformative learning through social interaction, social connectedness, cooperation and collaboration..." (p.641). Their approach is explicit about a 'language' of positive relationships providing a link between the promotion of trust through naturalistic opportunities for positive language and communication. We suggest then, that it is the provision of naturalistic and 
spontaneous opportunities for positive language and communication that is frequently missing in interventions designed to promote SEL in SEBD pupils. It is this link that we shall go on to explore.

\section{Methodology:}

We now provide a methodological overview of our two research studies which were both focused on relational approaches to SEBD. Further detail can be found in Warin and Hibbin (2016b). In 2015 we conducted our Comparative Nurture Group Study (CNGS) study, looking at the use of Nurture Groups (NGs) and principles of a 'nurture' focused ideology. This provided the springboard for our current research examining the use of Restorative Practice (RP) which aims to understand how RP supports schools in managing challenging behaviour and embedding RP as a whole school ethic.

The CNGS examined the use of NGs in seven schools in the North West (Warin \& Hibbin, 2016a, 2016b). We sampled five settings that utilised traditional NGs, and two alternative settings without NGs but utilising approaches strongly based upon nurturing principles and Attachment Theory. Our sampling criteria was based on Bennett's overview (2014) of influences on NG outcomes in tandem with the suggestions of a consultant, 'critical friend' Educational Psychologist who made recommendations to us.

We visited each setting on three occasions conducting individual interviews and focus groups with senior leaders, mainstream class teachers and NG specialists. We also undertook observations in both the NG and mainstream class and collected Boxall profiles and other relevant data including evidence of academic progress. In a few instances, we were also able to interview parents.

All interviews were semi-structured and based around themes emerging from the data in an iterative process between data collection and analysis in line with our Grounded Theory research methodology (Charmaz, 2006). Interview and Focus Group questions focused on: staff training; staff perceptions of nurture, behaviour management strategies used in the mainstream class and the NG, the school exclusion policy, the impact of nurture on the child, the role of leadership; communication strategies and parental engagement.

We also carried out two child case studies within each school through informal conversations with the child and where possible with the parent/carer. The selection of these 14 children was deliberately varied with a mix of gender, age group, and types of social and emotional difficulties. In addition, we were 
particularly interested in children who had the experience of being reintegrated into mainstream classes. The selection was made in consultation with staff and parents.

This study provided the authors with the understanding that the NG settings that were most successful in Nurture also had a leaning towards RP through avoiding punitive sanction systems and sustaining positive relationships. This paved the way for our current ongoing study of RP practices and outcomes.

Our ongoing research explores the use of RP in a range of educational settings including 5 primary schools, 2 secondary schools, 2 SEN Colleges and 1 Pupil Referral Unit. We established a democratic partnership approach between the research team and the key stakeholders using a bespoke system of evaluation, RUFDATA, devised by Saunders, (2000). The acronym is derived from seven evaluation components: Reasons and Purpose; Uses; Foci; Data; Audience; Timing; and Agency. The procedure requires the research team to collaborate with key stakeholders, the school project co-ordinators (SPCs), to identify and interpret the seven elements providing a shared stake in the findings and a clear vision of purposes. Each participating school decided how we should examine $\mathrm{RP}$ in relation to their unique educational and socio-cultural contexts, resulting in the exploration of a range of themes chosen by themselves. These include: the impact of RP on attendance; staff and students understanding of RP; peer mediation strategies between pupils; parental involvement; support for students' emotional wellbeing and development; transfer of RP between older and younger pupils; and the impact of coaching groups on whole school RP. This has resulted in a multi-dimensional data collection strategy including the use of questionnaires in some settings (this strategy has been of most use in baselining staff understandings of RP), and focus groups and interviews in all settings, to explore the bespoke focus identified by each school.

Analysis of the qualitative data produced in both studies uses the Constructivist Grounded Theory presented by Charmaz (2006) which advocates a principle of openness to the data and a method of constant comparison. Our findings from the CNGS emphasised the importance of school relationships, and the concept of behaviour as communication (Warin \& Hibbin, 2016a). This interest in relationality and communication now informs our analysis of the current RP data. We have maintained an interest in language-based effects, stemming from a pre-existing academic concern over the importance of language to children's education, wellbeing and development (Hibbin, 2013; Hibbin, 2016a, 2016b, Hibbin, In Press). Our analysis highlights the effects of language on the way 
that Nurture and RP are delivered, and we focus on these effects in four mainstream settings (2-4) and one SEND setting (5) across the two studies:

1) Auden Downs Secondary (Through) School - RP

2) Herdwick Primary School - CNGS

3) Beckworth Grange Secondary School - RP

4) Redferne Primary School - CNGS

5) Dale View Residential School - CNGS

\section{Ethical Considerations:}

Informed consent for participation has been gained for both studies through strategies recommended and approved by Lancaster University, through the use of participant information sheets and signed consent forms for staff, students and parents. Within the CNGS, we discussed the ethical issues implicated in our individual child case studies, with the Heads in each setting and the NG practitioners that were charged with their care. In negotiation with school Heads, willingness to engage on the part of children and their carers/parents was established as a key participation principle. The NG staff then took on the necessary gate-keeping responsibility for explaining the research to the NG children we would be observing, as well as liaising with parents and carers to ensure informed consent was freely given.

All school names have been anonymised and professional roles have been referred to throughout as oppose to assigning individuals pseudonyms.

\section{Findings re Positive Language and Communication:}

Our findings from both research studies serve to highlight the importance of positive language and communication and pedagogical initiatives that are designed to strengthen students' inter-relational ability and their understanding of self and others. Positive language and communication, in both studies, is centred around four particular areas: 1) developing emotional literacy; 2) using inquiring language; 3 ) meaningful opportunities for self-expression and listening skills; and 4) staff development to maintain staff awareness and modelling of positive communication practices. The latter finding emerged from the settings that had the highest value for creating consistent positive relationships amongst staff interactions, as well as in staff/pupil relationships, creating positive forms of communication 'from the top' (Warin, 2017). We now discuss each of these four areas. 


\section{Emotional Literacy:}

In a number of settings within the CNGS, there was a recognition that emotional literacy was often lacking for children from socially disadvantaged backgrounds and a history of broken emotional attachments. For example, in Dale View Residential School, a residential home for children from the most serious backgrounds of neglect and abuse (for example, one child has Dissociative Identity Disorder as a result of sexual abuse suffered during infancy), the developmental nature of emotional literacy was recognised, and language deprivation was seen to be at the root of many of the children's psycho-social issues. As a result, this setting gave priority to speech and language therapy which was built into the curriculum on a weekly basis:

“...we see a lot of language deprivation. So they haven't been hugged or gazed at, loved. They haven't had stories. They haven't had songs sung to them ...So our speech and language therapist...can show the low levels of the vocabulary naming skills at the beginning, and they just blossom once they get the environment where everybody's talking with them reading to them, bedtime stories and all these kinds of things." (Head: Dale View Residential School /CNGS)

Similarly, in Herdwick Primary School the specialist NG teacher used a 'Talking Turtle' to encourage children to feel comfortable speaking in front of a group, and the 'Emotional Thermometer' to access how they were feeling at any one time. They would pass the soft toy around the group and the children would give a numerical value to how 'upset', 'angry', or 'sad' they were feeling at that particular moment, before talking about ways they could be helped to reduce the negative affect they were experiencing:

"...my year twos we pass the Talking Turtle round and they'll say "I'm a one today because" ...or "I'm a two today"...It interests me that those feelings could have happened in the past and yet those feelings are staying with them and impacting on how they're feeling now... and then we talk about, "Well if you are a four, what could you do to make yourself be a three or a two" or "What could other people do to help you be that". (NG Teacher: Herdwick Primary School/CNGS)

In Redferne Primary School, there was a specific focus on emotional literacy. This setting stood out from the other mainstream schools in its strong focus on relational approaches overall and their framework for embedding emotional literacy into the whole school. The Head had created a model for learning called 
the 'Rounded and Grounded Framework' (Tomlinson, 2010) - a framework of prosocial behaviours and attitudes for learning based on the work of Guy Claxton (2002).



Figure 1: Rounded and Grounded Framework (Tomlinson, 2010)

The R\&G Framework was presented on a large wall display in each classroom to enable the class teacher to refer to it throughout the school day to highlight both positive and negative behaviours that children displayed at different times, or the kinds of learning that they wanted to see. The rationale was that it gave teachers a pedagogical mnemonic to support prosocial attitudes and dispositions, and the children a language and understanding of the emotional attributes that the school was trying to develop and instil. Some of these words in the R\&G Framework may at first seem quite advanced for primary age children from Reception onwards. However, as noted by Procter-Legg (2018), it is important not to 'dumb it down for children' and he goes on to suggest that this is particularly the case for children with SEND. Rather we need to "identify 
where children [are] on their cognitive development trajectory and introduce suitable language at the right time" (Procter-Legg, 2018; p.54)

\section{Inquiring language:}

Within RP restorative questioning is a highly equitable approach that aims to hear all voices, including the person who has caused the initial harm. It employs inquiring language that builds scripted questions into the post-conflict milieu. This questioning strategy invites thought processes surrounding the harm that has been perpetrated and ways to make reparation to be explored, asking:

- What happened?

- What were you thinking about at the time?

- What have your thoughts been since?

- How do you feel about what's happened?

- Who has been affected by what you did?

- In what ways have they been affected?

- What do you think should be done to repair the harm? (IIRP, 2006; online)

Such questions contrast with more adversarial questioning that is often used to reveal the reasons why the transgressor did what they did, and the appropriate punishment for their behaviour (O'Connell, 2004). The latter more reactive style that tries to shut down the behaviour and discipline the child, can often lead to incorrect assumptions as to the actual cause of the infraction resulting from a desire to deal with conflict swiftly. Research by Kajdukova (2014) suggests that SEBD students are "often picked upon and made scapegoats by their mainstream teachers" and find it immensely difficult to shed an entrenched school reputation for difficult behaviour, with the consequence that mainstream teachers seem to be "less willing to listen to their side of story" (p.140). In addition, a zero-tolerance approach provides SEBD children with a model of authoritarian discipline that they are used to reacting back against. As a result, practically speaking "direct confrontation may just lead to escalation" (Greenwood, 2002; p.303).

The way the restorative questions are formulated is important. The absence of 'why' questions and a focus instead on 'what', 'how' and 'who' is significant for children with SEBD who frequently do not know themselves why they may have behaved in a particular way and are unable to self-regulate in the heat of 
the moment. At such times it is demanding for these children to be asked selfreflecting questions about the causes of their behaviour. In addition, the way that questions are asked is of significance; one secondary school teacher suggested that "you want to develop your questioning so you're not stacking your questions" (Coaching Lead: Auden Downs Secondary School/RP) stressing a value for asking one question at a time rather than asking multiple questions that are complex and perhaps muddled for the students to answer in a clear and accurate way. Similarly, it has been suggested that avoiding nonmeaningful responses is important; as noted by Procter-Legg (2018) upon asking restorative questions you may initially "get a superficial response from those taking part...but if you asked a fourth time, people might start saying what they actually feel" (p.54).

The use of explicit inquiring language also emerged from the CNGS where the NG teacher talked about questioning the children in ways that allowed them to reflect on their own psycho-social development, and to think about changes in themselves and others since entering the NG:

"But I ask them explicit questions like, "How do you feel you are different since you've come to this class". And then I get other children to say, "Can you tell me any changes so and so has made?" - and they're really good at saying. What we do is a lot of explicit language if you know what I mean." (NG Teacher: Herdwick Primary School/CNGS)

It is important to note that while questions and inquiring language are essential to a restorative approach the tone and emotional affect connected to such questions needs to be taken into account. When questioning takes an adversarial stance that is more akin to an inquisition than an open dialogue, the result will be defensive behaviour from those being questioned. The Integrated Arts Therapist who worked in one of the most effective NG provisions, emphasised the need to offer reassuring responses and staying calm (Warin \& Hibbin, 2016a). Such an approach was considered essential to effective practice when dealing with challenging behaviour. Furthermore, restorative conferences where teachers are doing the mediating between an adult and a pupil who have come into conflict, can inadvertently replicate traditional adult/pupil power dynamics. A student commented:

"With the pupils you say what you want to say, but with the teachers, you feel like you can't say what you want to say because they are a teacher and they have a higher-you have to respect them more...the mediation I've been in, it has been equal, but some teachers feel like they have more power over the kids" (Student: Beckworth Grange Secondary School /RP) 
Clearly then, it is ineffective to ask restorative questions in the absence of a calm emotional climate, and without being mindful of traditional power dynamics. Such interactions are unlikely to produce an outcome that repairs the harm and sustains future relationships.

In addition to practices described above, when teachers ask questions in the post conflict context, they buy time for a more considered and less reactive response. It is a fundamental aspect of working with SEBD children to develop "our own capacities to be empathetically available, while remaining detached to be able to stop and think before acting" (Greenwood, 2002, p.307, authors' emphasis). Similarly, active forms of listening where teachers attend to the emotional pattern behind the words of their pupils are necessary to foster an empathetic response that targets the "masked expression of feelings or needs" (Rogers \& Farson, 1957; p.4-7) that the child may be unable to verbally express.

It is a challenging task for professionals working with children whose behaviour in the case of ACEs results from past damage, to remain 'empathetically available'. In such instances, teachers may themselves be feeling a variety of negative emotions in response to the 'secondary abuse' (Cairns, 1999) that students with SEBDs and/or ACEs can and often do inflict upon those around them. Clear thinking and responses that are helpful to the child (Greenwood, 2002) are unlikely to come easily under such circumstances. Therefore, the inquiring language of restorative questioning during these times allows the opportunity to take a breath and step back from the behaviour, allowing a more helpful and considered response to be given. This connects to the opportunity for reflection provided by silence which is a further aspect of inquiring language that often goes overlooked. Ollin (2008) has explored the value of silence in an educational context, calling for a reconceptualization of silence away from an 'absence of talk', towards a silent pedagogy of reflection that is "free from intrusion or the demand for an immediate response or interaction with others" (p.276).

\section{Self-expression and Listening Skills:}

One beacon of good practice that stood out within the RP research study was Auden Downs Secondary School, a 'through-school' school in a disadvantaged area of the North East that had created a 'Coaching Group' structure based on a circle-time formation within their school. The purpose of this strategy was to "build relationships and trust and expectation and commitment and loyalty to each other" (Head: Auden Downs Secondary School/RP). Coaching Groups 
were vertically structured groups combining approximately 8-10 children from Years 7-12 that met three times a week on a Monday morning to 'check-in' and a Friday afternoon to 'check-out', with a strategy known as 'Coaching Plus', that took place midweek on a Wednesday morning. The main idea of these groups was to ease the students into and out of the school week, being mindful of the impact of transitions on students' wellbeing. Coaching Plus was used as a vehicle to deliver the PSHE curriculum where two small Coaching Groups would come together to form one large group, and they would tackle a variety of subjects such as criminal behaviour, financial literacy and anger management. Within Coaching Plus relationships were "developed even further between staff and pupils but also between pupils and pupils" (Senior Assistant Principal: Auden Downs Secondary School/RP). It was clear in this setting that "the characters and competencies that emerge in terms of oracy" (Coaching Lead: Auden Downs Secondary School/RP) was a fundamental part of the way that the Coaching Groups worked. Students were provided with an opportunity to talk and to listen to others in structured self-supporting groups. Whilst this was clearly of benefit to all the students, it is likely to have been of particular help to SEBD students in learning how to self-monitor and support their social language and understanding of self and others. The Head in this setting pointed out the benefits for students making the transition from year 11 to year 12 post16 providers:

"The children are very well-prepared for that next step because they know how to talk to people, they know how to listen. They've learnt how to express themselves and be confident in themselves. They've got good self-identity. So what we're told by the post-16 providers is that they, anecdotally, they say as soon as they see a [school name] child, they just give them a place." (Head: Auden Downs Secondary School/RP)

The time and attention given to coaching groups and circles here, conveys a powerful message that the child's voice matters. Similarly, as well as their timetabled speech and language sessions, Dale View Residential School of the CNGS provided spontaneous opportunities for oracy. For example, an outdoor seating area, fire pit and storyteller's chair had been created in the school grounds, for fireside storytelling. Hibbin $(2013,2016 a)$ has shown that oral storytelling is a powerful tool for children's psycho-social wellbeing and development, with its benefits being "arrived at through a complex of processes tied to self-expression, identification, empathic understanding of self and others, and bi-directional communication" (p.11). The spontaneous speech and listening that occur within storytelling can bring about "transformative learning through social interaction [and] social connectedness" Hromek \& Roffey (2009; p.641). 
Of course, it is resource intensive to allocate time and space for these kinds of talking and listening opportunities. This is why the NG strategy adopts a much higher than usual teacher/pupil ratio. Guidance on NG provision recommends that the "number of children attending the Nurture room full time should normally be between eight to 10 children... with one full-time nurture teacher and a full-time Nurture classroom assistant" (DE, 2017; p.2-3). It is also why Auden Downs Secondary School was mindful of the fact that they needed to employ every available staff member in the delivery of their Coaching Group model, which we will discuss in more detail below.

\section{4. 'Top down' practices in positive communication:}

Adults need to be mentally healthy and feel that they are listened to, to enable them to listen to others. Warin et al. (2006) advocates the provision of selfreflective opportunities for teachers in supportive conversations with peers. She cites the classic work of Rogers (1967, p. 51) who says "if I can form a helping relationship to myself - if I can be sensitively aware of and acceptant toward my own feelings - then the likelihood is great that I can form a helping relationship toward another". A whole school relational ethos is created by a strong leadership who understand and act on the power of listening (Warin, 2017). Buy-in from the whole staff base is central to the establishment and maintenance of this kind of ethos. Employment of staff who share these values is necessary at the point of recruitment. In addition, it is often necessary to provide intensive training for staff. Auden Downs Secondary School of the RP study is a prime example of this where there was ongoing and continuous inhouse training for different staff members.

"We spend a lot of time about training around how to develop relationships, whether that's through the coaching programme or whether that is through...people observing each other in classrooms or the inclusion team delivering sessions. So they do get the theory part of it around the social discipline window and the restorative questions, but the training that is given is very much in-house and delivered by our members of staff." (Senior Assistant Principal: Auden Downs Secondary School/RP)

The coaching model used in this setting required the participation of each and every staff member, including administrative and welfare staff, due to the student/staff ratio demands of the coaching. Alongside delivering Coaching Groups to students, staff had their own Coaching Groups on a Monday that enabled them to feel supported and listened to by their teaching colleagues in school as advocated by Warin (2006). We observed a newly appointed member of administrative staff who was being trained as a coach. She would spend a 
number of months learning how to coach and would observe others during 'meet your coach days' before she reached the point where she felt suitably confident to take on her own coaching group. Upon asking her whether she felt daunted at the prospect of taking on a pastoral role when she wasn't a qualified teacher, she suggested that the school invested so much time training her in the relational approaches of RP and coaching, that when the time came she felt she would be suitably prepared. Similarly, in Beckworth Grange Secondary School of the RP project, there was also a strong emphasis upon the training of staff, and in particular we noted an encouraging significance being placed upon training around positive language use:

"So staff have training every two years on language to use, not just in restorative conversations, but in the classroom...we talk through different scenarios with staff, ones that they might come up against, and what's maybe a natural response - a response we might go to if we hadn't had training - and what's a better way of using language in that situation, and using restorative language rather than what's your go to anger response." (SENCO: Beckworth Grange Secondary School /RP)

\section{Creating a facilitating environment through positive communication practices:}

We must create 'facilitating' environments in schools that allow the child to feel emotionally 'held' and "known in all his bits and pieces" (Winnicott, 1945; p.150), if we are to provide fully inclusive environments for all children, including those with SEBD. Such environments should develop an embedded relational approach based around meaningful opportunities for positive language and communication. This does not preclude or render unnecessary the need for specialist interventions, but rather they should be seen as a complementary element within a whole school ethos of positive language and communication that is designed to bolster a fundamentally relational approach to the education, wellbeing and development of children and young people in school.

If we take the view that all behaviour is communication, it is important to try and understand how our own pedagogical language can contribute to this understanding. Knussen (2018) suggests that that we need to reframe the way we see challenging behaviour and accordingly change the language that surrounds it. Knussen's (2018) advice is to relabel 'challenging behaviour' as 'distressed behaviour' in recognition of the emotional origin of that behaviour 
within the child, rather than the difficulty that the behaviour creates for us as adults. This child-centred conception of problematic behaviour is seen by Knussen (2018) to result in a qualitatively different adult response, from prevention to stop the "challenge from recurring...to 'distress' ...to offer comfort" (Knussen, 2018; Online)

Changing our orientation towards the behaviours that typifie children and young people with SEBD involves a parallel change in the language we use to describe it. Relational approaches such as Nurture and Restorative Practice remind us that children's 'challenging' behaviour is not pre-mediated, but rather it is most often a knee-jerk reaction to internal stress and distress (Winnicott, 1954, 1956; Greenwood, 2002). This entails a change on the part of the staff members so that they can mentally reorient their response to a nurturing one that recognises that such children in the case of SEBD are traumatized. The reorientation of language in this way reminds us not to take challenging, distressed behaviour as a personal affront but rather to view it as an opportunity to find out what may be causing distress for that particular child in the moment.

\section{Conclusion:}

In the schools with the best RP and NG practices, we have found an emphasis on relationships (attachment) and positive communication. We have also found a recognition that teachers must themselves be skilful communicators, and empathetic listeners before they can hope to instil these practices in the children and young people they care for. Where it works well there is a communicative 'give and take' at every level of the school where warm and continuous relationships are prioritised. Overall, we saw that the positive language and communication-based strategies in both research projects relied on three clear indicators of relationality in school, namely consistency, equity and trust.

In terms of consistency, it is only when strategies are practiced as a matter of routine that they become embedded over time. This was the case with the Rounded and Grounded Framework that was displayed on the wall of every classroom of Redferne Primary School in the CNGS, providing both teachers and students with a visual prompt to the aims of emotional literacy and learning that were valued and encouraged by the school. In addition, the Coaching Groups in Auden Downs Secondary School of the RP project that took place every Monday, Wednesday and Friday, provided students with regular opportunities to engage with positive language and communication with a core group of individuals through the duration of their whole time at school. As 
noted by Procter-Legg (2018), relational approaches such a RP don't produce instant results; for some students, learning how to self-regulate and see things from the perspectives of others is a long game, often taking years. This may be a frustrating process for schools, but a necessary one - consistency is key.

The principle of equity is linked to the approach taken in Auden Downs Secondary School of the RP project, where an ethos of 'equity over equality' was explicitly fostered as part of the school ethos. The rationale for this was to inculcate an understanding that different pupils are treated differently according to need, taking into account apparent poor behaviour as a sign of internal distress:

"...when we've worked with some other schools is, a barrier that they tend to come up with, they talk about pupils thinking it will be unfair if different pupils were treated differently... we've done a lot of work with our pupils talking around equity and equality...it's important that people are treated differently because everybody comes from a different starting place." (Coaching Lead: Auden Downs Secondary School/RP)

Equity over equality is in the spirit of both Nurture and RP where a primary realisation is to recognise behaviour as communication and adopt the inquiring language of restorative questioning where everyone's voice is heard, including the transgressor's. The principle of fairness is particularly pertinent for children with SEBD who, as highlighted by Hajdukova (2014), can be left feeling scapegoated by teachers not willing to listen to their side of story, but are acceptant of discipline as long as they perceive it to be fair.

Finally, the principle of trust was engendered in both studies through meaningful and 'naturalistic' opportunities for social engagement (Hromek \& Roffey, 2009). An inclusive approach to children with SEBD relies on the strategic creation of spaces for positive language and trust that is built up through communication. In our studies these opportunities were opened up through the use of nurture groups, and whole-school nurturing approaches such as the use of circle times, coaching groups and storytelling. It takes a considerable degree of trust and the creation of an emotionally secure environment to be able to tell a fireside story, or to disclose emotionally sensitive information to a group. This aspect was best described by the Coaching Lead in Auden Downs Secondary School of the RP project:

"... in my coaching group, with one of my coachees, she started talking about the experience she had when her dad died... Because it's what you expect if people feel safe, calm and trust, then you get higher levels of disclosure." 
In addition, trust is established through the way we engage with relational approaches in school; an emotional tone that emphasises calm and reassurance when things go wrong is essential to the establishment of trust through unconditional positive regard (Rogers, 1951). Schools need to encourage teachers to model positive language use and communication and employ the kind of inquiring language that does not condemn but rather seeks to understand. In addition, strategies need to be applied consistently, discipline and behavioural support needs to be equitable, and the promotion of trust should be a primary aim. We fully recognise that it is easy for us to make such recommendations and very tough to implement them. However, until such relational practices become a mainstream way of viewing and responding to children and young people's often distressed (and therefore challenging) behaviour, students with SEBD will continue to experience the sharp end of punitive strategies in schools that are designed to manage the behaviour, rather than help the child. 


\section{References:}

Ainscow, M., T. Booth, and A. Dyson. 2006. Improving Schools, Developing Inclusion. London: Routledge.

Beitchman, J.H., Hood, J., Rochon, J. and Peterson, M., (1989). Empirical classification of speech/language impairment in children II. Behavioral characteristics. Journal of the American Academy of Child \& Adolescent Psychiatry, 28(1), pp.118-123.

Bennett, H. (2015) Results of the systematic review on nurture groups' effectiveness, The International Journal of Nurture in Education, 1 (1) 3- 7.

Boxall, M. (2002). Nurture groups in school-principles and practice. Gateshead: Paul Chapman Publishing.

Braithwaite, J., (1989). Crime, Shame and Reintegration. New York: Cambridge University Press.

Brown Hajdukova, E., (2015). Capturing the perspectives of students with social, emotional and behavioural difficulties on their schooling experiences. Unpublished thesis.

Cairns, K. (1999) Surviving Paedophilia, Stoke on Trent: Trentham Books.

Charmaz, K. (2006). Constructing grounded theory: A practical guide through qualitative analysis. Sage.

Claxton, G. (2002). Building learning power: Helping young people become better learners (Vol. 9). Bristol: TLO.

Cohen NJ, Davine M, Horodezky N, Lipsett L, Isaacson L. (1993) Unsuspected language impairment in psychiatrically disturbed children: prevalence and language and behavioral characteristics. J Am Acad Child Adolesc Psychiatry. 32:595-603.

Cooper, P. and Tiknaz, Y., (2007). Nurture Groups in school and at home: Connecting with children with social, emotional and behavioural difficulties (Vol. 1). Jessica Kingsley Publishers.

DE (2017). Nurture Group Provision: Guidance for schools. Available online: https://www.educationni.gov.uk/sites/default/files/publications/education/Nurture\%20Group\%20Provi sion\%20-\%20Guidance\%20for\%20Schools.pdf

Department of Education and Science. (1981). Education Act. London: DES. 
DFE. (2011). Support and Aspiration: A New Approach to Special Educational Needs. London: DFE.

DfE (2015) Special educational needs and disability code of practice: 0 to 25 years Statutory guidance for organisations which work with and support children and young people who have special educational needs or disabilities. Available online:

https://assets.publishing.service.gov.uk/government/uploads/system/uploads/att achment_data/file/398815/SEND_Code_of_Practice_January_2015.pdf

DfE (2018). Permanent and Fixed Period Exclusions in England: 2016 to 2017. Available:

https://assets.publishing.service.gov.uk/government/uploads/system/uploads/att achment_data/file/726741/text_exc1617.pdf

DfE (2018). Special educational needs in England: January 2018. Available online:

https://assets.publishing.service.gov.uk/government/uploads/system/uploads/att achment_data/file/729208/SEN_2018_Text.pdf

DfES (2001) SEN Code of Practice on the Identification and Assessment of Pupils with Special Educational Needs \& SEN Thresholds: Good Practice Guidance on Identification and Provision for Pupils with Special Educational Needs London: DfES.

DfES (2004). Removing Barriers to Achievement: SEN Strategy.

Felitti, V.J., Anda, R.F., Nordenberg, D., Williamson, D.F., Spitz, A.M., Edwards, V. and Marks, J.S., (1998). Relationship of childhood abuse and household dysfunction to many of the leading causes of death in adults: The Adverse Childhood Experiences (ACE) Study. American journal of preventive medicine, 14(4), pp.245-258.

Göransson, K., and C. Nilholm. 2014. "Conceptual Diversities and Empirical Shortcomings-a Critical Analysis of Research on Inclusive Education." European Journal of Special Needs Education 29 (3): 265-280.

Gray, C.A. and Garand, J.D., (1993). Social stories: Improving responses of students with autism with accurate social information. Focus on autistic behavior, 8(1), pp.1-10.

Greenwood, A. (2002). The child who cannot bear to feel. Psychodynamic Practice, 8(3), 295-310. 
Gualtieri, C.T., Koriath, U., Van Bourgondien, M. and Saleeby, N., (1983). Language disorders in children referred for psychiatric services. Journal of the American Academy of Child Psychiatry, 22(2), pp.165-171.

Hibbin, R. (2013). Paying lip-service to speaking and listening skills: Oral storytelling, arts-based education and the hegemony of literacy practices in primary school.

Hibbin, R. (2016a). The psychosocial benefits of oral storytelling in school: developing identity and empathy through narrative. Pastoral Care in Education, 34(4), 218-231.

Hibbin, R. (2016b). Oral storytelling, speaking and listening and the hegemony of literacy: Non-instrumental language use and transactional talk in the primary classroom. Changing English, 23(1), 52-64.

Hibbin, R. (In Press). A psychodynamic analysis of Nurture and RP: Positive language and communication through relational approaches in school.

International Journal of Nurture in Education.

Hodas, G.R., (2006). Responding to childhood trauma: The promise and practice of trauma informed care. Pennsylvania Office of Mental Health and Substance Abuse Services, 177.

Hromek, R., \& Roffey, S. (2009). Promoting Social and Emotional Learning With Games: "It's Fun and We Learn Things". Simulation \& Gaming, 40(5), 626-644.

Hopkins, B. (2011) Restorative Classroom Practice, Transforming Conflict, Optimus Publishing.

House of Commons. (2006). Special educational needs. Third report of sessions 2005-6. Available online:

https://publications.parliament.uk/pa/cm200506/cmselect/cmeduski/478/47807. $\underline{\mathrm{htm}}$

Irby, D. J. (2014). Trouble at school: Understanding school discipline systems as nets of social control. Equity and Excellence in Education, 47(4), 513-530.

Jull, S.K., (2008). Emotional and behavioural difficulties (EBD): the special educational need justifying exclusion. Journal of Research in Special Educational Needs, 8(1), pp.13-18.

Knussen, J. (2018) 'Little People Matter' - Time to change our thinking on 'challenging behvaiour' in the classroom. Available online:

http://aceawarescotland.com/wp-content/uploads/2018/09/ACE-Aware-MediaHerald-02092018.pdf 
Kupchik, A., (2010). Homeroom security: School discipline in an age of fear. NYU Press.

Lloyd, C., (2008). Removing barriers to achievement: a strategy for inclusion or exclusion?. International Journal of Inclusive Education, 12(2), pp.221-236.

Lorenz, S. (1998). Effective in-class support: The management of support staff in mainstream and special schools. London: David Fulton.

McInerney, M. and McKlindon, A., (2014). Unlocking the door to learning: Trauma-informed classrooms \& transformational schools. Education Law Center, pp.1-24.

Nicoll, W.G., (2014). Developing Transformative Schools: A ResilienceFocused Paradigm for Education. International Journal of Emotional Education, 6(1), pp.47-65.

O'Connell, T. (2004, August). Building a global alliance for restorative practices and family empowerment. Paper presented at the 5th International Institute of Restorative Practices Conference, Vancouver, Canada.

Ollin, R. (2008). Silent pedagogy and rethinking classroom practice: Structuring teaching through silence rather than talk. Cambridge Journal of Education, 38(2), 265-280.

Pane, D.M. and Rocco, T.S., (2014). Transforming the school-to-prison pipeline: Lessons from the classroom (Vol. 60). Springer Science \& Business Media.

Parsons, C., (2005). School Exclusion: The Will to Punish 1. British Journal of Educational Studies, 53(2), pp.187-211.

Perraudin, F., (2018). Pupil brings legal action against school's isolation policy: Available online:

https://www.theguardian.com/education/2018/dec/11/pupil-brings-legal-actionagainst-schools-isolation-booths-outwood-grange-academiestrust?CMP=share btn_tw

Perraudin, F., (2019). Mother sues over daughter's suicide attempt in school isolation booth. Available online: https://www.theguardian.com/education/2019/apr/03/isolation-of-children-atacademies-prompts-legal-action?CMP=Share_iOSApp_Other 
Procter-Legg, T. (2018) How to become a restorative school: Part 1 Embracing it. Available online: https://www.tes.com/news/how-become-restorative-schoolpart-1-case-embracing-it

Procter-Legg, T. (2018) How to become a restorative school: Part 3 Tackling the Challenges. Available online: https://www.tes.com/magazine/article/howbecome-restorative-school-part-3-tackling-challenges

Reimer, K. E. (2015). Restorative Justice as a Window into Relationships: Student Experiences of Social Control and Social Engagement in Scotland and Canada (Doctoral dissertation, Faculty of Education, University of Ottawa).

Rix, J., Sheehy, K., Fletcher-Campbell, F., Crisp, M. and Harper, A., (2013). Continuum of education provision for children with special educational needs: Review of international policies and practices.

Rogers, C. R. (1951) Client-centered Therapy: Its Current Practice, Implications and Theory. Boston: Houghton Mifflin.

Rogers, C. R., \& Farson, R. E. (1957). Active listening. Industrial Relations Center of the University of Chicago.

Rogers, C.R. (1967) A therapist's view of psychotherapy. London: Constable. Saunders, M. (2000). Beginning an evaluation with RUFDATA: theorizing a practical approach to evaluation planning. Evaluation, 6(1), 7-21.

SENDA (2001). Special Educational Needs and Disabilities Acts. Available online:

http://www.legislation.gov.uk/ukpga/2001/10/pdfs/ukpga_20010010_en.pdf

Soodak, L.C., Podell, D.M. and Lehman, L.R., (1998). Teacher, student, and school attributes as predictors of teachers' responses to inclusion. The Journal of Special Education, 31(4), pp.480-497.

Tickle, T., (2017). 'People give up': the crisis in school support for children with special needs. Available online:

https://www.theguardian.com/education/2017/sep/05/crisis-in-support-for-senchildren-ehc-plans

Tomlinson, R., (2010). Rounded and Grounded Framework. Available online: http://barrowford.lancs.sch.uk/page-40

UNESCO (1990). World Declaration on Education for All and Framework for Action to Meet Basic Learning Needs. Inter-Agency Commission. 
UNESCO (1994). Final report - World conference on special needs education: Access and quality. Paris: UNESCO

Wagner, M., Friend, M., Bursuck, W.D., Kutash, K., Duchnowski, A.J., Sumi, W.C. and Epstein, M.H., (2006). Educating students with emotional disturbances: A national perspective on school programs and services. Journal of Emotional and behavioral Disorders, 14(1), pp.12-30.

Walkley, M. and Cox, T.L., (2013). Building trauma-informed schools and communities. Children \& Schools, 35(2), pp.123-126.

Warin, J., Maddock, M., Pell, A., \& Hargreaves, L., (2006) Resolving identity dissonance through reflective and reflexive practice in teaching, Reflective Practice, 7:2, 233-245

Warin, J. (2017). Creating a whole school ethos of care. Emotional and Behavioural Difficulties, 22(3), 188-199.

Warin, J., \& Hibbin, R. A. (2016a). A study of nurture groups as a window into school relationships. The International Journal of Nurture in Education, 2, 714.

Warin, J and Hibbin, R. (2016b) Comparative Nurture Group Study. Final Report. NGN

Warnock, H.M., (1978). Special educational needs: Report of the committee of enquiry into the education of handicapped children and young people (Vol. 7212). Stationery Office Books (TSO).

Webster-Stratton, C. and Reid, M.J., (2004). Strengthening social and emotional competence in young children-The foundation for early school readiness and success: Incredible Years Classroom Social Skills and Problem-Solving Curriculum. Infants \& Young Children, 17(2), pp.96-113.

Willmann, M. and Seeliger, G.M., (2017). SEBD inclusion research synthesis: a content analysis of research themes and methods in empirical studies published in the journal Emotional and Behavioural Difficulties from 19962014. Emotional and Behavioural Difficulties, 22(2), pp.142-161.

Winnicott DW (1945). Primitive emotional development. In: Through paediatrics to psychoanalysis, p. 145-56. New York: Basic Books, 1975.

Winnicott DW (1956). Primary maternal preoccupation. In: The maturational processes and the facilitating environment, p. 300-5. New York: Int. Univ. Press, 1965. 
Yell, M. L. (1998). The legal basis of inclusion. Educational Leadership, 56(2), 70-73.

Zehr, H. (2002). The little book of restorative justice. Intercourse, PA: Good Books 